\title{
Upaya Peningkatan Citra Pembelajaran IPS Bermakna di Indonesia
}

\author{
Rini Setyowati ${ }^{1)}$, Wira Fimansyah ${ }^{2)}$ \\ 1) STKIP Singkawang, Singkawang, Indonesia \\ E-mail:rini1989setyowati@gmail.com \\ 2)STKIP Muhammadiyah Bangka Belitung \\ E-mail:wirafimansyah89@gmail.com
}

\begin{abstract}
Abstrak. Konsep pendidikan IPS di Indonesia secara historis epistemologis terasa sangat sukar karena dua alasan yaitu di Indonesia belum ada lembaga profesional bidang IPS sekuat pengaruh NCSS atau SSEC dan pembelajaran IPS sangat tergantung pada pemikiran individual atau kelompok pakar. Pembelajaran IPS yang bermakna diperlukan agar siswa dapat berkomunikasi dengan terampil. Selain itu , mengajar dengan diskusi memungkinkan siswa untuk mengembangkan pemahaman tentang isu tertentu, meningkatkan keterampilan berpikir kritis dan untuk meningkatkan keterampilan interpersonal. Pentingnya diskusi dalam pelajaran IPS mempertahankan argumen yang meliputi fakta dan konsep yang mendukung gagasan bahwa siswa yang mengalami keterlibatan pada kegiatan, interaksi kelompok kecil dan pembelajaran kooperatif lebih sukses dalam pembelajaran IPS
\end{abstract}

Keywords: pembelajaran IPS bermakna, keterampilan berfikir kritis, keterampilan interpersonal

\section{PENDAHULUAN}

Ilmu Sosial adalah studi terintegrasi dari ilmu-ilmu sosial dan humaniora untuk kompetensi sipil. IPS merupakan integrasi beberapa disiplin ilmu seperti antropologi, arkeologi, ekonomi, geografi, sejarah, hukum, filsafat, ilmu politik, psikologi, agama, dan sosiologi, serta disiplin ilmu yang sesuai dari humaniora, matematika dan alami ilmu.

Pengembangan materi IPS dengan ciri pembelajaran terpadu menggunakan geografi sebagai landasan (platform) kajian. Proses pembelajaran IPS di SMP, tidak menekankan pada aspek teoritis keilmuannya, melainkan lebih menekankan pada segi praktis mempelajari, menelaah, serta mengkaji gejala dan masalah sosial. Peserta didik diharapkan lebih memahami permasalahan sosial yang terjadi di lingkungan sekitarnya dan mampu berpikir kritis dalam menyikapi masalah tersebut.

Pembelajaran IPS di SMP disajikan dengan konsep atau topik/tema dari berbagai cabang ilmu sosial secara terpadu. Pembelajaran terpadu dapat dipandang sebagai suatu upaya untuk memperbaiki kualitas pendidikan, terutama dalam rangka mengimbangi gejala penjejalan materi yang sering terjadi dalam proses pembelajaran. Diharapkan dengan pembelajaran IPS secara terpadu, peserta didik dapat lebih mudah memahami hakikat keilmuan secara keseluruhan dan memahami masalah dengan berbagai sudut pandang sehingga dihasilkan solusi yang tepat untuk mengatasi masalah tersebut.

Konsep Pendidikan IPS di Indonesia secara historis epistemologis terasa sangat sukar karena dua alasan yaitu di Indonesia belum ada lembaga profesional bidang IPS sekuat pengaruh NCSS atau SSEC dan pembelajaran IPS sangat tergantung pada pemikiran individual atau kelompok pakar. Pembelajaran IPS bertujuan untuk melatih siswa berfikir kritis dan tanggap dalam pemecahan masalah dalam masyarakat. Namun fakta yang terjadi di sekolah, tidak semua siswa memiliki persepsi yang positif terhadap pembelajaran IPS. Pembelajaran IPS di sekolah cenderung tekstual. Guru hanya mengajarkan konsep-konsep yang ada dalam buku dan tidak diaplikasikan dalam kehidupan seharihari. Dibutuhkan kreativitas para guru dalam menerapkan pembelajaran IPS yang bermakna.Penelitian ini merupakan hasil kajian literatur untuk memberikan pemahaman tentang penerapan pembelajaran IPS yang bermakna agar citra IPS di Indonesia semakin baik.

\section{METODE}

Penelitian menggunakan metode kajian literatur dalam upaya untuk memberikan pemahaman penerapan pembelajaran IPS secara bermakna dengan mengkaji dari beberapa hasil penelitian dari jurnal dan buku.

\section{HASIL DAN PEMBAHASAN}

Tujuan utama dari pembelajaran IPS adalah untuk membantu kaum muda mengembangkan kemampuan membuat keputusan sebagai warga negara dari beragam budaya, masyarakat demokratis di dunia saling tergantung. Selama ini pembelajaran IPS di Indonesia dan berbagai negara lain masih kurang menarik. Salah satu penyebab utamanya adalah faktor guru. Kemampuan guru membelajarkan IPS secara bermakna, sehingga IPS menjadi 
mata pelajaran yang menarik dan menantang masih kurang. Selain masalah guru, menurut Zamroni,(Zamroni, n.d.) masalah lain pendidikan IPS adalah kurang tegasnya body of knowledge IPS di Indonesia. Meskipun didukung oleh berbagai sumber belajar seperti guru, rencana kreatif pelajaran, pelatihan intern, dukungan orangtua dan dukungan sekolah tetap saja siswa sering memiliki sikap negatif terhadap IPS.

Beberapa faktor yang mempengaruhi persepsi terhadap IPS yang diungkapkan Haladyna \& Shaughnessy (Zamroni, 2008) bahwa tiga faktor memiliki korelasi langsung dengan sikap siswa antara lain guru, lingkungan belajar, dan sikap siswa yang sudah terbentuk sebelumnya yang meliputi motivasi, rasa percaya diri, dan pengakuan pentingnya materi pelajaran. Lingkungan belajar memainkan peran yang kuat dalam membentuk sikap siswa yang berpotensi terhadap ilmu sosial.

Faktor guru seperti komitmen untuk membantu siswa belajar, antusiasme dalam kelas dan perhatian individu sangat terkait dengan sikap siswa terhadap materi pelajaran. Pengaruh guru dapat menciptakan lingkungan belajar yang positif di dalam kelas. Iklim kelas dan sikap siswa dapat dimodifikasi melalui intervensi untuk meningkatkan citra IPS.

Tujuan pembelajaran IPS (Somantri, M, 2001) adalah menjadikan peserta didik menjadi ahli ekonomi, politik, hukum, sosiologi, ahli pengetahuan sosial lainnya, menjadi warga negara yang baik dari pengintegerasian beberapa disiplin ilmu sosial. Pembelajaran IPS juga diharapkan mampu menampung peserta didik meneruskan pendidikan ke universitas maupun langsung dapat menerapkan dalam kehidupan dalam masyarakat. Pembelajaran IPS yang bermakna diharapkan dapat memberikan kesempatan kepada peserta didik dalam mempelajari masalah- masalah sosial dalam masyarakat. Mager (Zamroni, 2008) mengatakan bahwa sikap dan persepsi adalah kunci untuk keberhasilan siswa, karena beberapa berkaitan dengan beberapa alasan. Sikap terhadap kelas atau guru yang santai berhubungan dengan prestasi. siswa yang memiliki sikap positif terhadap suatu materi pelajaran lebih mungkin untuk melanjutkan pendidikan mereka dalam mata pelajaran atau mungkin melanjutkan pendidikan mereka melalui pelatihan teknis, perguruan tinggi, atau sekolah pascasarjana. Ketiga, siswa menyampaikan sikap mereka tentang sekolah kepada orang tua, guru, dan teman-teman. Jika sikap mereka secara keseluruhan terhadap sekolah negatif dapat meningkatkan kemungkinan bahwa siswa akan menyampaikan sikap negatif tentang ilmu-ilmu sosial dengan orang lain.

Menurut Zamroni (Zamroni, n.d.), arah pendidikan ilmu-ilmu sosial di Indonesia memberikan kontribusi maksimal dalam proses mempercepat pembangunan. Untuk tujuan, materi, dan organisasi pelaksanaan pembelajaran ilmu-ilmu sosial perlu dirumuskan secara lebih komprehensif. Tujuan itu dirumuskan dalam suatu bentuk kompetensi yang harus dikuasai oleh siswa setelah mengikuti pendidikan pada jenjang tertentu. Untuk jenjang pendidikan dasar tujuan tersebut paling tidak mencakup empat aspek. Pertama, memiliki kemampuan menjelaskan konsep-konsep dan teori-teori dalam ilmu-ilmu sosial. Kedua, memiliki critical thinking dan kemampuan pengambilan keputusan yang langsung mempengaruhi mereka, Ketiga, memiliki trust dan emphaty serta mengaplikasikan etika dan norma dalam pengambilan keputusan, baik dalam arti substansi maupun prosedural. Keempat, memiliki efikasi, kemampuan kontrol diri, kreativitas dan kemampuan untuk melakukan inovasi, serta kemampuan berkerjasama.

Berbagai metode yang bervariasi sangat penting untuk memberikan siswa kesempatan untuk berdebat atau bahkan berdebat selama itu tidak keluar dari materi yang dibahas dalam kelas. Pembelajaran dengan dengan diskusi dan memungkinkan umpan balik siswa berarti membantu siswa meningkatkan kemampuan mereka untuk berpikir. Hasil dari diskusi kelas adalah bahwa siswa dapat berkomunikasi dengan terampil. Selain itu, mengajar dengan diskusi memungkinkan siswa untuk mengembangkan pemahaman tentang isu tertentu, meningkatkan keterampilan berpikir kritis dan untuk meningkatkan keterampilan interpersonal. Siswa mengungkapkan pentingnya diskusi dalam pelajaran IPS mempertahankan argumen yang meliputi fakta dan konsep yang mendukung gagasan bahwa siswa yang mengalami keterlibatan pada kegiatan, interaksi kelompok kecil dan pembelajaran kooperatif lebih sukses dalam studi kelas sosial. Selain itu, antusiasme guru dan kreativitas sebagai cara untuk meningkatkan kinerja siswa di sekolah.

Guru harus bisa menunjukkan antusias yang tinggi dalam pelajaran IPS dan memberikan motivasi kepada siswa untuk aktif dalam pembelajaran. Masalah sosial itu dekat dengan kehidupan siswa dan menekankan pentingnya membuat keputusan dalam hidup bermasyarakat. Untuk menjawab tantangan di atas Zamroni (Zamroni, n.d.) menawarkan tiga alternatif mempersipakan langkah ke depan penataan IPS. Pertama, membangun disiplin akademik sebagai core discipline. Dasar keilmuan dalam IPS harus tegas sebagai basis keilmuan yang tidak akan hilang. Kedua, mengembangkan social efisensi, perguruan tinggi perlu merencanakan pembelajaran yang memberi pengalaman mahasiswa merancang pembelajaran IPS. Ketiga, mengembangkan peran social reconstructivist, dengan mempersiapkan mahasiswa dengan karakter yang senantiasa memerang ketidakadilan di masyarakat dengan rekayasa sosial.

Guru memainkan peran penting dalam membentuk sikap siswa tentang ilmu sosial. Guru yang bersedia untuk membantu siswa dalam belajar, menunjukkan antusiasme di dalam kelas, dan mencermati kebutuhan siswa memiliki efek yang kuat pada bagaimana siswa memandang IPS. Guru yang efektif mampu menciptakan iklim belajar yang positif di dalam kelas. Pengaturan ruang kelas kedua dan siswa sikap dapat diubah untuk meningkatkan pikiran siswa IPS (Khaled Alazzi, 2011)

Hasil penelitian (Setyowati et al., 2016) dalam melaksanakan pembelajaran IPS guru sebaiknya menerapkan pendekatan scientific dengan model problem based learning 
yang terbukti efektif terhadap kompetensi sikap, pengetahuan dan keterampilan peserta didik dengan menyesuaikan sesuai materi yang tepat terkait permasalahan social, 2) Apabila guru menginginkan peserta didik dapat mencapai ketuntasan pada kompetensi sikap, sebaiknya guru menggunakan pendekatan scientific dengan model problem based learning, karena dapat melatih peserta didik menunjukkan sikap sosial yang baik misalnya peduli dan saling menghargai/toleransi antar peserta didik selama proses pembelajaran berlangsung, 3) Apabila guru menginginkan peserta didik dapat meningkatkan hasil belajar pada kompetensi pengetahuan, sebaiknya guru menggunakan pendekatan scientific dengan model problem based learning, karena memungkinkan peserta didik tidak hanya belajar satu arah dari guru ke peserta didik tetapi juga antar sesama peserta didik, 4)Apabila guru menginginkan peserta didik dapat mencapai ketuntasan pada kompetensi keterampilan, sebaiknya guru menggunakan pendekatan scientific dengan model problem based learning karena dapat melatih peserta didik mengemukakan pendapat, bertanya, menjawab dan mempresentasikan hasil diskusinya serta memiliki ide kreatif pada produk yang dipresentasikan, 5)Sebaiknya dilakukan kerjasama antar guru dalam menerapkan pendekatan scientific dan model problem based learning untuk memberikan hasil belajar baik pada pembelajaran IPS dengan penyusunan materi yang tepat.

Sikap menyumbang sebagian besar untuk kesuksesan guru. Pertama, bagaimana seorang siswa dinilai guru dikaitkan dengan potensi siswa untuk mengembangkan sikap terbuka tentang mata pelajaran. Kedua, siswa yang memiliki sikap positif terhadap mata pelajaran lebih mungkin untuk terus menjadi fokus pada mata pelajaran tertentu. Ketiga, perasaan siswa tentang sekolah membantu positif membentuk hubungan dengan orang tua, guru, dan teman sebaya.

Hasil penelitian (Allazi, 2004:1) menyatakan siswa merasa pentingnya pendidikan yang solid, termasuk pendidikan IPS, pembelajaran aktif, dan antusiasme guru. Semua elemen ini membantu untuk membentuk sikap positif pada siswa. Guru memainkan peran utama dalam seberapa baik siswa memiliki persepsi tentang pelajaran, membuat siswa mencintai ilmu sosial atau tidak menyukai. Pembelajaran IPS mengajarkan siswa pengetahuan Siswa menyatakan kekhawatiran mereka tentang metodologi pengajaran dan pelajaran yang membosankan yang diakibatkan guru memiliki sedikit pengetahuan tentang materi dan metode pengajaran. Semua siswa menyatakan perlunya kegiatan aktif dalam pembelajaran seperti diskusi kontes, dan game untuk mampu menjawab pertanyaanpertanyaan yang menantang. Peningkatkan citra pembelajaran ilmu pengetahuan sosial sebagai bagian dari kurikulum antara lain iklim kelas, antusiasme guru, metodologi, dan pengalaman sebelumnya yang faktor utama. Siswa mengungkapkan bahwa banyak guru terus bergantung pada buku teks dan kuliah sebagai alat utama untuk mengajar yang membuat pembelajaran kurang menarik. Hasil penelitian (Enok Maryani, 2009) adalah Pengembangan keterampilan sosial sangat tergantung pada guru sebagai pengembang kurikulum. Oleh karena itu, memahami misi kurikulum IPS, kemampuan transdisipliner, multi disiplin, cooperative study dalam memecahkanmasalah sosial, harus dikuasai oleh setiap guru IPS, disamping kemampuan pengaplikasian metode, media, sumber belajar dan asesmen yang bervariasi.Pengembangan keterampilan sosial sangat tergantung pada guru sebagai pengembang kurikulum.

Guru perlu menyadari perbedaan antara siswa: berbagai tingkat kecerdasan, gaya belajar yang berbeda, dan perbedaan yang berkaitan dengan pemahaman pemahaman materi. Karena perbedaan ini, guru tidak hanya harus menyadari, tetapi juga mempelajari perbedaan dan menggunakan berbagai strategi mengajar untuk memastikan bahwa semua siswa memiliki pendidikan yang berkualitas. Hal ini sangat penting bahwa guru mengevaluasi berbagai metode, sebelum menerapkan kepada setiap siswa. Hal ini penting bagi guru untuk memahami bahwa guru merupakan faktor kunci dalam persepsi siswa tentang IPS. Ketika guru menggunakan strategi pengajaran yang berbeda untuk memperbaiki iklim belajar, itu adalah mungkin bahwa sikap positif tentang ilmu sosial akan terjadi(K Alazzi, 2004)

Hasil penelitian (Deddy wahyudi, 2011) Guru seharusnya mengerti intelegensi peserta didik melalui berbagai metode pengukuran intelegensi, sehingga baik dalam perencanaan, proses pembelajaran hingga evaluasi belajar, guru dapat dengan mudah untuk mengoptimalkan pembelajaran IPS. Kurikulum yang dipersiapkan guru sebaiknya berisi materi atau topik pelajaran yang mau dipelajari peserta didik bersifat tematik, sehingga peserta didik akan lebih tertarik untuk mengikuti proses pembelajarna dan tercapai pembelajaran IPS yang meaningful. Hasil penelitian (W.Warni, 2013) adalah guru perlu lebih meningkatkan penggunaan model pembelajaran yang lebih mengaktifkan siswa, misalnya penggunaan model pembelajaran yang lebih kontekstual, kooperatif dan kolaboratif, inkuiri, dan pembelajaran yang berbasis masalah sehingga pembelajaran khususnya IPS menjadi lebih menarik dan bermakna. Pembelajaran IPS hendaknya dapat menumbuhkan sikap sosial pada siswa.

\section{KESIMPULAN}

Pembelajaran IPS yang bermakna diperlukan agar siswa dapat berkomunikasi dengan terampil. Selain itu , mengajar dengan diskusi memungkinkan siswa untuk mengembangkan pemahaman tentang isu tertentu, meningkatkan keterampilan berpikir kritis dan untuk meningkatkan keterampilan interpersonal. Siswa mengungkapkan pentingnya diskusi dalam pelajaran IPS mempertahankan argumen yang meliputi fakta dan konsep yang mendukung gagasan bahwa siswa yang mengalami keterlibatan pada kegiatan, interaksi kelompok kecil dan pembelajaran kooperatif lebih sukses dalam studi kelas sosial. Selain itu, antusiasme guru dan kreativitas sebagai cara untuk meningkatkan kinerja siswa di sekolah. Guru harus bisa menunjukkan antusias yang tinggi dalam pelajaran IPS dan memberikan motivasi kepada siswa untuk aktif dalam pembelajaran. Masalah sosial itu dekat dengan 
kehidupan siswa dan menekankan pentingnya membuat keputusan dalam hidup bermasyarakat.

\section{UCAPAN TERIMAKASIH}

Penelitian ini terlaksana atas dukungan STKIP Singkawang dan STKIP Muhammadiyah Bangka Belitung.

\section{DAFTAR PUSTAKA}

Alazzi, K. (2004). Students' perceptions of social studies: a study of middle school and high school students in jordan. International Journal Of Scholarly Acadmic Intellectual Diversity, Volume 6.

Alazzi, K. (2011). Teachers Perceptions and Conceptions of Global Education: A Study of Jordanian Secondary Social Studies Teachers. Global Education Journal, September(3), 78-94. Retrieved from http://web.a.ebscohost.com/abstract?direct=true\&profi le $=$ ehost $\&$ scope $=$ site $\&$ authtype $=$ crawler $\&$ jrnl $=215236$ 22\&AN=73151107\&h=JksEKIL53Y6cDkudWpU0d5 Yd0wMkZ3tbJu1iE3tj\%2Bm\%2BMnyzLOlt4i\%2BD HKUEUgsyjrhvF\%2FrB9U7JnAavm94jg\%2Fw\%3D $\% 3 \mathrm{D} \& \mathrm{crl}=\mathrm{c} \&$ resultNs $=$ AdminWebAuth\&result

Deddy wahyudi. (2011). O l e h : D e d d y W a h y u d i ABSTRAK Hasil belajar peserta didik berdasarkan dimensi Pembelajaran IPS terdiri dari knowledge , skills , behavior dan action, kenyataannya, pembelajaran IPS di Indonesia pada umumnya dan di
Kabupaten Bangkalan pada kh. Jornal Pendidikan, (1), 33-45.

Enok Maryani, H. S. (2009). Pengembangan Program Pembelajaran Ips Keterampilan Sosial. Jurnal Penelitian Vol., 9 Nomor 1(1), 1-111.

Setyowati, R., Mulyani, E., Yogyakarta, U. N., Setyowati, R., Mulyani, E., \& Yogyakarta, U. N. (2016). Harmoni Sosial : Jurnal Pendidikan IPS Volume 3 , No 1 , Maret 2016 ( 74-81) Online : http://journal.uny.ac.id/index.php/hsjpi EFEKTIVITAS PENDEKATAN SCIENTIFIC DENGAN PBL DAN PROBLEM SOLVING THE EFFECTIVENESS OF SCIENTIFIC APPROACH WITH PBL AND PROBLEM , 3(1), 74-81.

Somantri, M, N. (2001). Menggagas Pembaharuan Pendidikan IPS. Bandung: UPI.

W.Warni. (2013). Journal of Educational Social Studies, 1(2). Retrieved from http://journal.unnes.ac.id/sju/index.php/jess/article/vie w/1300

Zamroni. (n.d.). Rekonstruksi konsep IPS di Indonesia. Retrieved January 29, 2014, from http://www.uny.ac.id/berita/rekonstruksi-konsep-ipsdi-indonesia.html.

Zamroni. (2008). Teaching social studies. Yogyakarta: UNY. 